\title{
The female athlete triad: a current concepts review
}

\author{
Christopher A George (MD) \\ James $P$ Leonard (MD) \\ Mark R Hutchinson (MD) \\ University of Illinois at Chicago, Department of Orthopaedic Surgery, Chicago, IL
}

\begin{abstract}
Female athletic participation continues to grow throughout the world. This has many positive effects on health and well-being, but it has also led to a unique set of health problems. The female athlete triad was first described in 1992 by the American College of Sports Medicine, consisting of disordered eating, amenorrhoea and osteoporosis. An updated position stand was released in 2007 that modified the components of the triad to energy availability, menstrual function and bone mineral density. This article reviews the current definitions of the triad components, epidemiology, pathophysiology, diagnosis and treatment. Each of the components of the triad exists on a continuum from healthy to pathological. Low energy availability, from either dietary restriction or increased expenditure, is the factor that leads to the pathological states of menstrual function and bone mineral density. Athletes especially at risk are those in sports requiring leanness or low body weight. Prevention and early recognition of triad disorders is crucial to ensure timely intervention and treatment. Treatment is centered on restoring energy availability to adequate levels $\left(30 \mathrm{kcal} \cdot \mathrm{kg}^{-1} \cdot \mathrm{d}^{-1}\right)$ to re-establish normal metabolic functioning. All those who work with female athletes must remain vigilant in the education, recognition and treatment of athletes at risk. Continued research and knowledge of the triad disorders aids the development of prevention and treatment strategies to allow women to continue to enjoy the benefits of regular exercise and physical activity throughout their lives.
\end{abstract}

\section{Introduction}

Similar to the increases seen in athletic participation within the United States, female athletic participation continues to increase worldwide. An examination of the participation of women in the Olympic Games

\section{CORRESPONDENCE:}

Mark R Hutchinson

University of Illinois Hospital at Chicago

Department of Orthopaedic Surgery

$835 \mathrm{~S}$ Wolcott Ave

$\mathrm{M} / \mathrm{C} 844$

Chicago, IL 60612

E-mail: mhutch@uic.edu over the last century appears to support this. Female participation has steadily increased, most dramatically over the past 50 years. The most recent summer Olympics in Beijing (2008) saw the highest rate of female participation with a total of 4746 women participating, representing a record $42 \%$ of athletes. Women remain underrepresented in sport in South Africa, but consistent and progressive rates of participation are being appreciated throughout the country. As rates of female participation continue to increase throughout the country, it is important to consider the unique health challenges that female athletes may encounter.

For most female athletes, sports participation is a positive experience, providing improved physical fitness, enhanced selfesteem and better physical and mental health. ${ }^{1}$ However, this increased activity has also led to the emergence of a unique combination of medical problems and injuries specific to the female athlete. This includes a unique triad to conditions specific to the female athlete that include energy availability, menstrual function and bone mineral density.

\section{Definitions}

In 1992, the American College of Sports Medicine (ACSM) recognised the association of three distinct entities with female athletes. The female athlete triad was originally defined as the combination of disordered eating, amenorrhoea and osteoporosis found in physically active girls and women. ${ }^{2}$ Further research since then proved these entities to be far too narrow in scope, existing only at the extreme endpoint of the disorder's spectrum. ${ }^{3}$ By 2007, the ACSM revised position statement modified the three components of the triad into energy availability, menstrual function and bone mineral density. ${ }^{4}$ Each of these components consists on a continuum from healthy to subclinical to pathological.

Energy intake from diet is necessary for various physiological functions. Energy expenditure is the energy expended by the body during normal daily activities and exercise training. Energy availability defines the amount of energy remaining for physiological functions after expended from physical activity. Decreased caloric consumption and/or increased exercise energy expenditure results in low energy available for normal physiology functions, including cellular maintenance, thermoregulation, growth and reproduction.

Clinical eating disorders, namely anorexia nervosa, bulimia nervosa and eating disorders not otherwise specified, exist on the extreme end of this category. However, these conditions carry a largely psychiatric component for diagnosis. ${ }^{5}$ A larger population of female athletes practise unhealthy eating and weight control behaviours with significant impact on their health without the psychiatric element. Such subclinical eating disorders include prolonged fasting, low caloric diets, binge eating, purging, or the 
utilisation of diet pills, laxatives and other supplements. Other athletes unknowingly fail to meet their considerable exercise energy requirements due to time constraints, food availability issues or lack of appropriate nutritional knowledge. ${ }^{6}$

Amenorrhoea is the absence of menstrual cycles, and can be subdivided into primary and secondary amenorrhoea. Primary amenorrhoea is the absence of menarche by age 15 , whereas secondary amenorrhoea is an interruption of menses for greater than 3 months after the initiation of menarche. ${ }^{7}$ The ACSM updated position stand on the female athlete triad recognised other menstrual irregularities that cause an adverse effect to the female athlete's health. ${ }^{4}$ Thus, the term menstrual dysfunction was employed as a component of the female athlete triad, which includes luteal suppression, anovulation and oligomenorrhoea in addition to primary and secondary amenorrhoea. Oligomenorrhoea describes a prolonged menstrual cycle greater than 35 days. ${ }^{8}$ Both luteal suppression and anovulation are asymptomatic conditions, associated with either a shortened luteal phase or lack of ovulation respectively.

Osteoporosis is a decrease in bone mass that increases the risk of fracture. ${ }^{9}$ This may be due to age-related decreases in bone mass, or the result of inadequate bone accumulation during growth and development resulting in a lower peak bone mass being attained. The World Health Organization (WHO) criterion for diagnosing osteoporosis is a bone mineral density more than 2.5 standard deviations below the mean of young adults. ${ }^{10}$ Utilisation of this T-score was based on epidemiological data relating bone mineral density to fracture risk in postmenopausal women, ${ }^{11,12}$ thus it lacks external validity for evaluating adolescent or premenopausal women. In 2005, the International Society for Clinical Densiometry (ISCD) recommended that bone mineral density for premenopausal women and children be expressed as a Z-score. A Z-score greater than or equal to 2.0 standard deviations below the mean of age- and sex-matched controls is defined as "low bone density below the expected age range.'. 13,14 Together the ISCD and ACSM defined osteoporosis in premenopausal women as having this low Z-score along with secondary clinical risk factors, including chronic malnutrition, eating disorders, hypogonadism, glucocorticoid exposure and previous fractures. $4,13,14$

\section{Epidemiology}

The prevalence of female athletes with abnormalities in energy availability, menstrual function and/or bone mineral density varies tremendously between studies. Reported data show a range of 1 . $62 \%$ of female athletes with an eating disorder, ${ }^{2,15} 6-79 \%$ with menstrual dysfunction, ${ }^{2,3,16}$ and $0-50 \%$ with low bone mineral density. ${ }^{17}$

Several factors have contributed to these broad results, including the wide range and ever-changing definitions of each component of the female athlete triad. Utilising the strict DSM-IV diagnosis for clinical eating disorders yields a prevalence between $1 \%$ and $3 \%{ }^{18}$ whereas the more ambiguous term 'disordered eating' opens up the diagnostic criteria, yielding larger prevalence outcomes between $15 \%$ and $62 \%{ }^{1}$ Similarly, the expanded definition of menstrual dysfunction to include oligomenorrhoea, luteal suppression and anovulation has seen prevalence increase from $6 \%$ to as high as $79 \%{ }^{16,19}$ Finally, studies utilising the WHO classification for bone mineral density found $22-50 \%$ of patients with osteopenia, and virtually $0 \%$ having osteoporosis. ${ }^{17}$ The new ISCD criterion utilizing Z-scores identified $10.7 \%$ of female athletes to have low bone mineral density below the expected age range. ${ }^{20}$

Other aspects involved in the investigation of the female athlete triad result in an imprecise measurement of prevalence. Diagnosis of low energy availability typically involves self-questionnaires. Most questionnaires are designed for clinical eating disorders, such as the Eating Disorders Inventory (EDI or EDI-2) or the Eating Attitude Test (EAT), ${ }^{21}$ and focus mostly on the psychiatric component of the disease. They do not take into account other subclinical causes of low energy availability, including excess exercise energy expenditure and abnormal eating behaviours. This can be better assessed with documentation of energy balance through food logs and activity records. However, both evaluations require self-reporting, with inherent limitations due to underreporting of symptoms. ${ }^{1}$

The heterogeneity of the population being investigated for the female athlete triad has also created discrepancies in prevalence. The age of an athlete significantly affects their risk for each component of the triad, as does their stage in growth, development and menarche. Thus, comparing athletes over a wide range of ages during adolescence and pre-adulthood becomes problematic. In addition, because females develop at different rates, comparing them at similar ages can also cause difficulties.

The level of competition also affects the epidemiological studies of the female athlete triad. Comparison of elite athletes, collegiate athletes and recreational athletes has shown an increase risk for components of the female athlete triad with increasing level of competition. A meta-analysis of 34 studies with 2459 athletes found an increased risk of disordered eating with elite athletes, and that non-elite athletes, especially those in high school, were somewhat protected. $^{22}$ Early start of sport-specific training and dieting, a sudden increase in training volume, and sports-related injury are also risk factors for the female athlete triad more commonly seen in higher-level athletics. ${ }^{23}$ The increased pressure for winning by the athletes, as well as coaches, parents and society in general, places these athletes at higher levels of competition at increased risk for behaviours associated with the female athlete triad. ${ }^{1}$

Different sports have different risk factors for the individual components of the female athlete triad. Low energy availability is more commonly seen in sports that emphasise a lean physique or low body weight (Table I). ${ }^{2}$ Byrne et al. ${ }^{24}$ identified $31 \%$ of elite female athletes in 'thin-build' sports to have an eating disorder compared with $8 \%$ in the 'normal-build' athletes. Thin-build athletes are those involved in sports emphasising leanness or low body weight (ballet, gymnastics, long distance running, swimming and diving), where normal-build athletes are those in sports with less emphasis on leanness (basketball, volleyball, hockey, softball). ${ }^{24}$ Menstrual dysfunction is more common in endurance sports such as running, with prevalence up to $69 \% .{ }^{25,26}$ High-impact sports such as basketball, volleyball and gymnastics ${ }^{20,27,28}$ are associated with higher bone mineral density than lower-impact sports such as

\section{TABLE I. Sport-specific risks to low energy availability}

\begin{tabular}{ll}
\hline Category & Examples \\
Sports subjectively scored & $\begin{array}{l}\text { Dance, figure skating, diving, } \\
\text { gymnastics, aerobics }\end{array}$
\end{tabular}

Sports emphasising low body Distance running, cycling, crossweight

Sports requiring body contour-revealing clothing country skiing

Volleyball, swimming, diving, cross-country running, crosscountry skiing, track, cheerleading

Sports with weight categories Horse racing, martial arts, wrestling, rowing

Sports emphasising prepuber- Figure skating, gymnastics, diving tal body habitus 
running and swimming. ${ }^{29}$ Consequently, studies examining single sports may either overestimate or underestimate the true overall prevalence of the female athlete triad.

Despite all the difficulties reporting on the female athlete triad, including inconsistent definitions, methodological issues and the heterogeneity of the population, three studies establish prevalence for the simultaneous diagnosis of all three components of the female athlete triad ${ }^{30-32}$ These studies utilised large, heterogeneous samples of athletes as well as a more validated definition of low energy availability, menstrual dysfunction and low bone mineral density. Disordered eating and menstrual dysfunction were determined from a questionnaire, while bone mineral density was evaluated via dualenergy X-ray absorptiometry (DXA). The resultant prevalence was between $1.2 \%$ and $4.3 \%$ of female athletes for all three components. However, these values are likely underrepresented because neither low energy availability nor subclinical menstrual disorders, including luteal suppression, anovulation and oligomenorrhoea, were part of the diagnostic criteria. Also, as discussed previously, self-reporting has inherent bias. Finally, although the prevalence is low for all components of the triad, one study ${ }^{31}$ found $6 \%$ of female athletes had two components of the female athlete triad and $18-24 \%$ had one component.

\section{Pathophysiology}

In addition to redefining the components of the female athlete triad, the ACSM focused on the pathogenesis of the female athlete triad. The majority of the current research on the female athlete triad centres on low energy availability as the key entity underlying the entire process.

A specific aetiology has not been identified regarding the pathogenesis of eating disorders or low energy availability. ${ }^{33}$ There likely is a complex relationship between social, cultural, demographic, environmental, biology, psychological and behavioural factors. ${ }^{34}$ Controversy exists regarding whether athletes have a higher prevalence of disordered eating behaviours when compared with non-athletes, with some studies showing increased prevalence in the athletic population, ${ }^{22,35,36}$ while others show no difference. ${ }^{37,38}$

However, there is evidence suggesting athletes face sportspecific pressures that may trigger eating disorders in vulnerable athletes. As discussed previously, sports with emphasis on low body weight place these athletes at increased risk for developing a clinical eating disorder. In addition, increased training and practice associated with organised athletics may lead to inadvertent low energy availability. Experiments have shown that dietary restriction increased hunger, but similar levels of energy deficiency by increased exercise expenditure did not increase appetite. ${ }^{39}$ As a result, athletes unknowingly do not increase their energy intake due to increased exercise expenditure due to a lack of a physiological response. ${ }^{40}$

Energy availability is not just related to diet and exercise, but also dependent on other hormonal and physiological processes. Two different hormones, leptin and ghrelin, have been identified as potential regulators of metabolic rate and energy homeostasis. The hormone leptin regulates the resting metabolic rate, and has been proposed as a marker of nutritional status. Leptin is decreased in athletes with disordered eating and amenorrhoea. ${ }^{41} \mathrm{~A}$ leptin value of $1.85 \mathrm{mg}$ has been identified as a minimum value to maintain a normal menstrual cycle. ${ }^{41}$ Ghrelin is a hormone produced in the stomach and gastrointestinal tract that acts as a metabolic signal for hunger and energy homeostasis. De Souza et al. ${ }^{42}$ showed high levels of ghrelin in amenorrhoeic women indicate an energy deficit. Ghrelin may also play a physiological role in reproductive function via actions on the luteinising hormone (LH) pulsatility. ${ }^{43}$
Increased physical activity has been linked to the cessation of menses. ${ }^{16}$ This has been found as a result of a disruption in the pulsatile secretion of LH by the pituitary gland, which is caused by a disruption earlier in the pulsatile secretion of the gonadotropinreleasing hormone by the hypothalamus. ${ }^{44}$ In multiple studies, Loucks showed that low energy availability is at the root of hypothalamic menstrual dysfunction. ${ }^{45-47}$ The threshold of energy availability necessary to maintain normal menstrual function in 30 kcal. $\mathrm{kg}^{-1}$ lean body mass per day. ${ }^{45}$ Strenuous training alone is not enough to disrupt menstrual function, unless it is also accompanied by dietary restriction. Normal cycles can be restored with increasing dietary intake; however, this is only accomplished with sustained increased intake, not simply one day of aggressive refeeding. ${ }^{46}$

Altered bone mineral density is related to deficiency in the hormones oestrogen and progesterone, as well as caloric deprivation and inadequate calcium intake. The most important function of oestrogen on bone health is its suppressing effect of osteoclast activity. ${ }^{48}$ BMD declines as the number of missed menstrual cycles accumulates and these losses may not be fully reversible. ${ }^{49} \mathrm{~A}$ study by Ihle and Loucks showed that low energy availability may have a direct effect of bone. ${ }^{50}$ They demonstrated markers of bone formation and resorption changed negatively within 5 days in sedentary women exposed to low energy availability through dietary restriction or increased exercise energy expenditure. It is plausible to expect similar results to be seen in an athletic population. Additional work by Zanker has shown that low BMI and an oestrogen deficiency were associated with disruption of bone formation in amenorrhoeic women. ${ }^{51}$ However, there was a lack of correlation between serum levels of bone formation markers, BMI and serum oestradiol concentration in the eumenorrhoeic athletes, suggesting that there may be a threshold value of BMI, or serum oestradiol concentration, above which bone formation is not influenced by either of these variables. In fact, markers of bone formation are low in athletes with menstrual dysfunction, suggesting that low bone formation is a result of undernutrition.

Additional studies have indicated that low energy availability affects other metabolites and hormones, such as insulin, growth hormone, insulin-like growth factor-1, cortisol and thyroid hormone. ${ }^{52}$ These are all important for optimal bone health and metabolism independent of a hypo-oestrogenic state.

\section{Health consequences}

The body compensates for low energy availability by decreasing the resting metabolic rate, resulting in decreased energy to other normal physiological mechanisms, such as cellular maintenance, thermoregulation, growth and reproduction. Thus, although a stable body weight may be maintained, the health of the athlete is adversely affected.

Sustained low energy availability can have significant effects on health. Undernutrition impairs both menstrual and skeletal heath. ${ }^{53}$ Additionally, several studies have shown medical effects and physical symptoms involving the dermatological, cardiovascular, endocrine, gastrointestinal, renal and central nervous systems (Table II). ${ }^{33,53-55}$ Montero et al. ${ }^{56}$ examined the effect of low energy availability on the immune system of the female athlete (Fig. 1). Increased exercise combined with low calorie intake seems to decrease immunocompetence, resulting in decreased endurance, decreased performance and increased chance of subclinical and clinical infections.

The effect that low energy availability has on athletic performance varies depending on the severity and duration of the low energy state, 
TABLE II. Physical symptoms of athletes with eating disorders

\begin{tabular}{|c|c|c|c|}
\hline Dermatological/dental & Cardiovascular & Endocrine & Gastrointestinal \\
\hline Hair loss & Bradycardia & Hypoglycaemia & Swollen parotid glands \\
\hline Lanugo hair & Hypotension & Delayed onset of puberty & Constipation/diarrhoea \\
\hline \multicolumn{2}{|c|}{ Dorsal hand callus or abrasions } & Menstrual dysfunction & Postprandial distress \\
\hline \multicolumn{2}{|l|}{ Dental and gum problems } & Stress fractures & \\
\hline & & \multicolumn{2}{|c|}{ CNS/Other } \\
\hline \multicolumn{2}{|c|}{ Dehydration } & \multicolumn{2}{|c|}{ Significant weight loss } \\
\hline \multicolumn{2}{|c|}{ Oedema } & \multicolumn{2}{|c|}{ Frequent weight fluctuations } \\
\hline \multicolumn{2}{|c|}{ Electrolyte disturbances } & \multicolumn{2}{|c|}{ Extreme fatigue } \\
\hline \multicolumn{2}{|c|}{ Hypokalaemia } & \multicolumn{2}{|c|}{ Muscle weakness } \\
\hline \multicolumn{2}{|c|}{ Muscle cramps } & \multicolumn{2}{|c|}{ Hyperactivity } \\
\hline \multicolumn{2}{|c|}{ Metabolic alkalosis } & \multicolumn{2}{|c|}{ Anaemia } \\
\hline
\end{tabular}

as well as the physical demands of the sport. ${ }^{57}$ Longer durations of restricted energy availability are associated with more dramatic negative effects on performance. ${ }^{57}$ Likewise, athletes in endurance sports with high energy demands (distance running, swimming, cycling, basketball) show more effects on performance than athletes in lower energy demand sports (gymnastics, diving, weightlifting).

The consequences of menstrual dysfunction have been well documented and include infertility, decreased immune function, increased cardiovascular risk factors and decreased bone mineral density with its associated increased risk of premature osteoporosis. $^{58}$ It should be emphasised to athletes that menstrual dysfunction is not a normal response to athletic training. Athletes may show little concern for disruption of their cycles and may even 'appreciate the break'. However, this should be viewed as a clear indication that health is being compromised.

An athlete's bone mineral density is a reflection of her cumulative history of energy availability and menstrual status, in combination with genetics and other environmental factors. It is important to always consider the current bone mineral density status and where it is moving along the spectrum. Stress fractures occur more frequently in females who display menstrual irregularities and/or low bone mineral

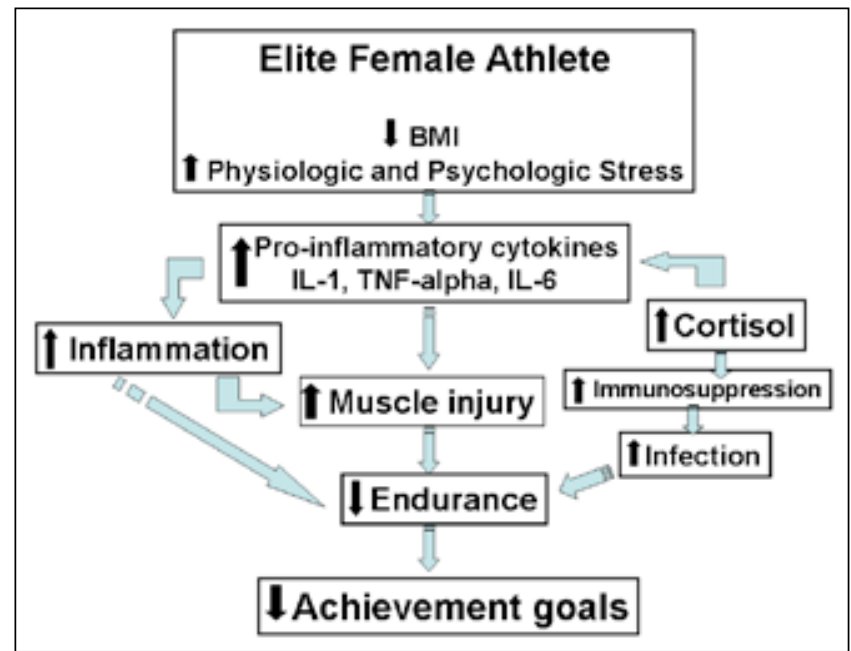

Fig. 1. Consequences of increased exercise and a low BMI in the female athlete. density. ${ }^{59,60}$ A premenopausal fracture not related to a significant traumatic event is a strong predictor for postmenopausal fractures. ${ }^{61}$ Even with restoration of adequate energy availability and regular menses the loss of bone mineral density may not be fully reversible.

\section{Screening and diagnosis of triad disorders}

Screening for and diagnosis of the triad disorders can be challenging due to the symptoms and health consequences not always being readily apparent. A high degree of suspicion and an understanding of the relationship between the triad components are critical to diagnosis. Many of the affected athletes are involved in those sports requiring leanness or thinness as an advantage in performance; however, individuals participating in any sport or regular physical activity are also at risk. Additionally, individuals of all levels may be at risk, not just the elite population. Optimal screening times are during pre-participation physicals and during annual heath exams. Other opportunities present when athletes are evaluated for related problems. Any time an athlete presents with one component of the triad, they should be assessed for the others.

\section{Energy availability/disordered eating}

A high index of suspicion is necessary for the recognition and diagnosis of disordered eating behaviours. Psychological or behavioural characteristics may alert the physician or other member of the health care team. Examples include: anxiety with eating or weight gain, unusual dieting behaviour, binging or secretive eating, social withdrawal, abuse of laxatives or other weight loss medications and over-exercising. ${ }^{62}$ Additionally, recognition of physical symptoms likely related to malnutrition and/or purging behaviours may be seen. ${ }^{62}$ Weight loss methods may include restriction of food intake, fasting, self-induced vomiting, diet pills, laxatives, diuretics and excessive exercise. $^{62}$ Physical exam is important in the recognition of eating disorders, and should start with height, weight and vital signs. Orthostatic hypotension should also be assessed. Other physical findings include cold or discoloured hands and feet, hypercarotenaemia, lanugo hair and parotid gland enlargement. Laboratory assessment should initially include a complete blood count with differential, chemistry profiles, erythrocyte sedimentation rate, C-reactive protein, thyroid function studies (and other sex steroid hormones depending on physical findings) and a urinalysis. An electrocardiogram should also be done to evaluate for any arrhythmias and prolongation of the QT interval. ${ }^{63}$ 


\section{Menstrual dysfunction}

Similar to identification of eating disorders, a high degree of suspicion, thorough history taking and physical exam are important in identification of menstrual dysfunction. Menstrual dysfunction commonly accompanies disordered eating, but if it continues after weight is restored to within $10 \%$ or normal, further workup for amenorrhoea is indicated. Patients with functional hypothalamic amenorrhoea often have a normal physical exam, but may show vaginal atrophy on pelvic exam if hypo-oestrogenism is present. Laboratory evaluation for secondary amenorrhoea should include a pregnancy test, gonadotropin measurement (FSH, LH), probating and thyroid studies. If there is evidence of androgen excess on physical exam, free testosterone and dehydroepiandrosterone sulfate may be obtained. Additional workup may be needed based on patient history and physical exam, as well as with cases of primary amenorrhoea. Consultation with a physician experienced in reproductive medicine is recommended if menses are not restored after $3-6$ months of treatment.

\section{Bone mineral density}

The gold standard for evaluation of bone mineral density is with DXA. Current recommendations for evaluation with DXA include those athletes with a history of stress fractures, fractures with minimal trauma, a history of hypo-oestrogenism, and disordered eating or eating disorders for a cumulative total of 6 months or more. ${ }^{64}$ It is important to remember that in normal female athletes, particularly those in weight-bearing sports, have bone mineral density measurements $12-15 \%$ higher than non-athletes. ${ }^{20}$ Altered bone mineral density may be obvious in the athlete with a stress fracture or fragility fracture. Additionally, affected athletes are also more likely to report sprains, strains and other soft-tissue injuries. ${ }^{65}$

\section{Treatment recommendations}

Prevention and treatment of the triad should employ a multidisciplinary team for best results. The health care team should include a physician, registered dietician and a mental health practitioner, especially for those athletes with eating disorders. Additional team members may include athletic trainers, an exercise physiologist, coaches, and parents and other family members.

\section{Prevention}

The best way to prevent the detrimental health effects of the triad components is through early recognition of athletes at risk and then incorporation of prompt education and intervention in those athletes. Special emphasis should be placed on optimising energy availability and maximising bone mineral accumulation in younger athletes. Athletes should be counselled on appropriate nutritional requirements for their age. Females of all ages should also be educated on the benefits of regular weight-bearing exercise for bone health. Athletes should be screened for menstrual dysfunction and educated on its immediate and long-term health negative health effects.

\section{Treatment}

The initial focus of treatment should be on modifying diet and exercise behaviour to increase energy availability. This may be accomplished by increasing energy intake, decreasing energy expenditure, or a combination of both. The aim is to restore normal menstrual cycling and prevent a further loss of bone. Energy availability should be increased to at least $30 \mathrm{kcal}^{\mathrm{k} \mathrm{kg}^{-1}}$ lean body mass per day, but increasing levels of energy availability over $45 \mathrm{kcal}^{-\mathrm{kg}^{-1}}$ lean body mass per day may be necessary to increase bone mineral density. ${ }^{45}$ It is important to ensure that adequate intake of the bone-building nutrients calcium $\left(1000-1300 \mathrm{mg} \cdot \mathrm{d}^{-1}\right)$, vitamin D $\left(400-800 \mathrm{lU} \cdot \mathrm{d}^{-1}\right)$ and vitamin $\mathrm{K}\left(60-90 \mu \mathrm{g} . \mathrm{d}^{-1}\right)$ is maintained. ${ }^{66,67}$ Athletes in intense training also require greater protein intake than for the general population $\left(1.2-1.6 \mathrm{~g} \cdot \mathrm{kg}^{-1} \mathrm{~d}^{-1}\right){ }^{68}$ Affected athletes without clinical eating disorders should be referred to a dietician for nutritional counselling. Those athletes with clinical eating disorders require consultation with other care providers, as well as individual psychotherapy, cognitive behavioural, group and family therapy. Increased energy availability continues until the resumption of menses and is maintained during training and competition. Athletes need to maintain minimum criteria to continue with training and competition. Close follow-up and open communication with the entire health care team is essential. Athletes who fail to maintain appropriate levels of energy availability, refuse treatment, or fail to improve eating behaviour should be withheld from training and competition to focus on their health.

In some athletes the addition of pharmacological therapy is beneficial in the treatment of triad disorders. Athletes with low energy availability secondary to clinical eating disorders may benefit from antidepressant medications. Antidepressants are also used in athletes with concomitant depression and anxiety disorders. ${ }^{69}$ The other established and recommended pharmacological treatments in athletes with the triad are aimed at maintenance and restoration of bone mineral density. In females with functional hypothalamic amenorrhoea, hormonal therapy, commonly oral contraceptive pills (OCP) are used to protect bone mineral density. When OCP are used to restore regular menstrual cycles, it will not normalise metabolic factors that impair bone formation, health and performance. Therefore it is unlikely to fully reverse low bone mineral density in this population, and studies have shown inconsistent osteogenic effects with OCP. ${ }^{70,71}$ Current indications for the initiation of treatment with OCP are females older than age 16 years with declining bone mineral density and persistent functional hypothalamic amenorrhoea despite adequate energy availability, with the goal of minimising further bone loss. ${ }^{70}$ Agents for increasing bone mineral density, such as bisphosphonates and selective oestrogen receptor modulators, are not recommended for use in premenopausal women. ${ }^{71}$ Bisphosphonates have not been proven effective in women of childbearing age. ${ }^{72}$ Additionally, they may be stored in the bone for many years, raising concern for possible harm to a fetus during pregnancy. ${ }^{73}$ Further research into the use of any currently available or novel forms of hormone therapy will be important in increasing bone mineral density in athletes with functional amenorrhoea.

\section{Summary}

Low energy availability, menstrual function and altered bone mineral density, in isolation or in combination, continue to pose significant health risks to female athletes. We continue to see progress in determining the aetiology, pathophysiology, recognition, diagnosis and management of the triad disorders. All those who work with female athletes should remain vigilant in the education, recognition and treatment of athletes at risk. Continued advancement of research efforts and knowledge of the triad disorders aiding in the development of prevention and treatment strategies will allow all women to continue to enjoy the benefits of regular exercise and physical activity throughout their lives.

\section{Declarations}

The manuscript has been read and approved by all listed co-authors, and meets requirements of co-authorship. This manuscript has not previously been published. There are no conflicts of interest for any of the authors. There are no other disclosures for the authors. 


\section{REFERENCES}

1. Nattiv A, Agostini R, Drinkwater B, Yeager KK. The female athlete triad. The inter-relatedness of disordered eating, amenorrhea, and osteoporosis. Clin Sports Med 1994;13(2):405-418.

2. Otis CL, Drinkwater B, Johnson M, Loucks A, Wilmore J. American College of Sports Medicine position stand. The Female Athlete Triad. Med Sci Sports Exerc 1997;29(5):i-ix.

3. Beals KA, Meyer NL. Female athlete triad update. Clin Sports Med 2007;26(1):69-89.

4. Nattiv A, Loucks AB, Manore MM, Sanborn CF, Sundgot-Borgen J, Warren MP. American College of Sports Medicine position stand. The female athlete triad. Med Sci Sports Exerc 2007;39(10):1867-1882.

5. American Psychiatric Association., American Psychiatric Association Task Force on DSM-IV. Diagnostic and Statistical Manual of Mental Disorders : DSM-IV. 4th ed. Washington, DC: American Psychiatric Association, 1998.

6. Beals KA, Manore MM. Behavioral, psychological, and physical characteristics of female athletes with subclinical eating disorders. Int J Sport Nutr Exerc Metab 2000;10(2):128-143

7. Current evaluation of amenorrhea. Fertil Steril 2004;82(1):266-272.

8. Otis CL. Exercise-associated amenorrhea. Clin Sports Med 1992;11(2):351-362.

9. Osteoporosis prevention, diagnosis, and therapy. JAMA 2001;285(6):785795.

10. Kanis JA, Melton LJ, 3rd, Christiansen C, Johnston CC, Khaltaev N. The diagnosis of osteoporosis. J Bone Miner Res 1994;9(8):1137-1141.

11. Hui SL, Slemenda CW, Johnston CC, Jr. Baseline measurement of bone mass predicts fracture in white women. Ann Intern Med 1989;111(5):355 361.

12. De Laet CE, Van Hout BA, Burger H, Weel AE, Hofman A, Pols HA. Hip fracture prediction in elderly men and women: validation in the Rotterdam study. J Bone Miner Res 1998;13(10):1587-1593.

13. Leslie WD, Adler RA, El-Haij Fuleihan G, et al. Application of the 1994 WHO classification to populations other than postmenopausal Caucasian women: the 2005 ISCD Official Positions. J Clin Densitom 2006;9(1):2230.

14. Diagnosis of osteoporosis in men, premenopausal women, and children J Clin Densitom 2004;7(1):17-26.

15. Byrne S, McLean N. Eating disorders in athletes: a review of the literature. J Sci Med Sport 2001;4(2):145-159.

16. Warren MP, Perlroth NE. The effects of intense exercise on the female reproductive system. J Endocrinol 2001;170(1):3-11.

17. Khan KM, Liu-Ambrose T, Sran MM, Ashe MC, Donaldson MG, Wark JD. New criteria for female athlete triad syndrome? As osteoporosis is rare, should osteopenia be among the criteria for defining the female athlete triad syndrome? Br J Sports Med 2002;36(1):10-13.

18. Brownell KD, Rodin J, Wilmore JH. Eating, Body Weight and Performance in Athletes: Disorders of Modern Society. Philadelphia: Lea \& Febiger, 1992:128-148.

19. Johnson C, Powers PS, Dick R. Athletes and eating disorders: the National Collegiate Athletic Association study. Int J Eat Disord 1999;26(2):179188.

20. Torstveit MK, Sundgot-Borgen J. Low bone mineral density is two to three times more prevalent in non-athletic premenopausal women than in elite athletes: a comprehensive controlled study. Br J Sports Med 2005;39(5):282-287.

21. Lebrun $\mathrm{CM}$. The female athlete triad: what's a doctor to do? Curr Sports Med Rep 2007;6(6):397-404.

22. Smolak L, Murnen SK, Ruble AE. Female athletes and eating problems: a meta-analysis. Int J Eat Disord 2000;27(4):371-380.

23. Sundgot-Borgen J. Risk and trigger factors for the development of eating disorders in female elite athletes. Med Sci Sports Exerc 1994;26(4):414419.

24. Byrne S, McLean N. Elite athletes: effects of the pressure to be thin. J Sci Med Sport 2002;5(2):80-94.

25. Abraham SF, Beumont PJ, Fraser IS, Llewellyn-Jones D. Body weight, exercise and menstrual status among ballet dancers in training. $\mathrm{Br} \mathrm{J} \mathrm{Ob}$ stet Gynaecol 1982;89(7):507-510

26. Dusek T. Influence of high intensity training on menstrual cycle disorders in athletes. Croat Med J 2001;42(1):79-82.

27. Nikander R, Sievanen H, Heinonen A, Kannus P. Femoral neck structure in adult female athletes subjected to different loading modalities. J Bone Miner Res 2005;20(3):520-528.

28. Meyer NL, Shaw JM, Manore MM, et al. Bone mineral density of olympiclevel female winter sport athletes. Med Sci Sports Exerc 2004;36(9):1594601.

29. Taaffe DR, Snow-Harter C, Connolly DA, Robinson TL, Brown MD Marcus R. Differential effects of swimming versus weight-bearing activity on bone mineral status of eumenorrheic athletes. J Bone Miner Res 1995:10(4):586-593.

30. Beals KA, Hill AK. The prevalence of disordered eating, menstrual dysfunction, and low bone mineral density among US collegiate athletes. Int J Sport Nutr Exerc Metab 2006;16(1):1-23.

31. Nichols JF, Rauh MJ, Lawson MJ, Ji M, Barkai HS. Prevalence of the female athlete triad syndrome among high school athletes. Arch Pediatr Adolesc Med 2006;160(2):137-142. 
32. Torstveit MK, Sundgot-Borgen J. The female athlete triad exists in both elite athletes and controls. Med Sci Sports Exerc 2005;37(9):1449-1459.

33. Rome ES, Ammerman S, Rosen DS, et al. Children and adolescents with eating disorders: the state of the art. Pediatrics 2003;111(1):e98-108.

34. Brownell KD, Foreyt JP. Handbook of Eating Disorders: Physiology, Psychology, and Treatment of Obesity, Anorexia, and Bulimia. New York: Basic Books, 1986

35. Sundgot-Borgen J. Prevalence of eating disorders in elite female athletes. Int J Sport Nutr 1993;3(1):29-40.

36. Sundgot-Borgen J, Torstveit MK. Prevalence of eating disorders in elite athletes is higher than in the general population. Clin $\mathrm{J}$ Sport Med $2004 ; 14(1): 25-32$

37. Taub DE, Blinde EM. Eating disorders among adolescent female athletes: influence of athletic participation and sport team membership. Adolescence 1992;27(108):833-848.

38. Reinking MF, Alexander LE. Prevalence of disordered-eating behaviors in undergraduate female collegiate athletes and nonathletes. J Athl Train 2005;40(1):47-51.

39. Hubert $P$, King NA, Blundell JE. Uncoupling the effects of energy expenditure and energy intake: appetite response to short-term energy deficit induced by meal omission and physical activity. Appetite 1998;31(1):9-19.

40. Truswell AS. Energy balance, food and exercise. World Rev Nutr Diet 2001;90:13-25.

41. Thong FS, McLean C, Graham TE. Plasma leptin in female athletes: relationship with body fat, reproductive, nutritional, and endocrine factors. J Appl Physiol 2000;88(6):2037-2044.

42. De Souza MJ, Leidy HJ, O'Donnell E, Lasley B, Williams NI. Fasting ghrelin levels in physically active women: relationship with menstrual disturbances and metabolic hormones. J Clin Endocrinol Metab 2004;89(7):3536-3542.

43. Schneider LF, Warren MP. Functional hypothalamic amenorrhea is associated with elevated ghrelin and disordered eating. Fertil Steril 2006;86(6):1744-1749.

44. Loucks AB, Mortola JF, Girton L, Yen SS. Alterations in the hypothalamic pituitary-ovarian and the hypothalamic-pituitary-adrenal axes in athletic women. J Clin Endocrinol Metab 1989;68(2):402-411.

45. Loucks AB, Thuma JR. Luteinizing hormone pulsatility is disrupted at a threshold of energy availability in regularly menstruating women. J Clin Endocrinol Metab 2003;88(1):297-311.

46. Loucks $A B$, Verdun $M$. Slow restoration of $L H$ pulsatility by refeeding in energetically disrupted women. Am J Physiol 1998;275(4 Pt 2):R1218-1226.

47. Loucks $A B$, Verdun $M$, Heath EM. Low energy availability, not stress of exercise, alters LH pulsatility in exercising women. J Appl Physiol 1998;84(1):37-46.

48. Riggs BL, Khosla S, Atkinson EJ, Dunstan CR, Melton LJ, 3rd. Evidence that type I osteoporosis results from enhanced responsiveness of bone to estrogen deficiency. Osteoporos Int 2003;14(9):728-733.

49. Keen $A D$, Drinkwater BL. Irreversible bone loss in former amenorrheic athletes. Osteoporos Int 1997;7(4):311-315.

50. Ihle R, Loucks AB. Dose-response relationships between energy availability and bone turnover in young exercising women. J Bone Miner Res 2004;19(8):1231-1240.

51. Zanker CL, Swaine IL. Relation between bone turnover, oestradiol, and energy balance in women distance runners. Br J Sports Med 1998;32(2):167-171.

52. De Souza MJ, Williams NI. Beyond hypoestrogenism in amenorrheic athletes: energy deficiency as a contributing factor for bone loss. Curr Sports Med Rep 2005;4(1):38-44.
53. Becker AE, Grinspoon SK, Klibanski A, Herzog DB. Eating disorders. N Engl J Med 1999;340(14):1092-1098.

54. Practice guideline for the treatment of patients with eating disorders (revision). American Psychiatric Association Work Group on Eating Disorders. Am J Psychiatry 2000;157(1 Suppl):1-39.

55. Golden $\mathrm{NH}$, Katzman DK, Kreipe RE, et al. Eating disorders in adolescents: position paper of the Society for Adolescent Medicine. J Adolesc Health 2003;33(6):496-503.

56. Montero A, Lopez-Varela S, Nova E, Marcos A. The implication of the binomial nutrition-immunity on sportswomen's health. Eur J Clin Nutr 2002:56 Suppl 3:S38-41.

57. Beals KA. Disordered Eating Among Athletes: A Comprehensive Guide for Health Profesisonals. Champaign, IL: Human Kinetics, 2004:70-71.

58. Constantini N. Clinical consequences of athletic amenorrhea. Sports Med 1994:17(4):213-223.

59. Bennell KL, Brukner PD. Epidemiology and site specificity of stress fractures. Clin Sports Med 1997;16(2):179-196.

60. Bennell K, Matheson G, Meeuwisse W, Brukner P. Risk factors for stress fractures. Sports Med 1999;28(2):91-122.

61. Wu F, Mason B, Horne A, et al. Fractures between the ages of 20 and 50 years increase women's risk of subsequent fractures. Arch Intern Med 2002;162(1):33-36.

62. Sundgot-Borgen J. Disordered eating. In: Ireland ML, Nattiv, A., eds. The Female Athlete. Philadelphia: Saunders, 2002:242-243.

63. Identifying and treating eating disorders. Pediatrics. 2003;111(1):204-211.

64. Khan AA, Hanley DA, Bilezikian JP, et al. Standards for performing DXA in individuals with secondary causes of osteoporosis. J Clin Densitom 2006;9(1):47-57.

65. Beals KA, Manore MM. Disorders of the female athlete triad among collegiate athletes. Int J Sport Nutr Exerc Metab 2002;12(3):281-293.

66. Bergman C, Gray-Scott D, Chen JJ, Meacham S. What is next for the Dietary Reference Intakes for bone metabolism related nutrients beyond calcium: phosphorus, magnesium, vitamin D, and fluoride? Crit Rev Food Sci Nutr 2009:49(2):136-144.

67. Greer FR, Krebs NF. Optimizing bone health and calcium intakes of infants, children, and adolescents. Pediatrics 2006;117(2):578-585.

68. Trumbo P, Schlicker S, Yates AA, Poos M. Dietary reference intakes for energy, carbohydrate, fiber, fat, fatty acids, cholesterol, protein and amino acids. J Am Diet Assoc 2002;102(11):1621-1630.

69. American Psychiatric Association. Treatment of patients with eating disorders, third edition. Am J Psychiatry 2006;163(7 Suppl):4-54.

70. Cumming DC, Cumming CE. Estrogen replacement therapy and female athletes: current issues. Sports Med 2001;31(15):1025-1031.

71. Liu SL, Lebrun CM. Effect of oral contraceptives and hormone replacement therapy on bone mineral density in premenopausal and perimenopausal women: a systematic review. Br J Sports Med 2006;40(1):11-24.

72. Miller KK, Klibanski A. Clinical review 106: Amenorrheic bone loss. J Clin Endocrinol Metab 1999:84(6):1775-1783.

73. Patlas N, Golomb G, Yaffe P, Pinto T, Breuer E, Ornoy A. Transplacenta effects of bisphosphonates on fetal skeletal ossification and mineralization in rats. Teratology 1999;60(2):68-73. 